\title{
UJI FUNGSI SISTEM NITRIDASI ION UNTUK PERLAKUAN PERMUKAAN
}

\author{
Suprapto, BA. Tjipto Sujitno, Sayono \\ Pusat Teknologi Akselerator dan Proses Bahan- BATAN
}

\begin{abstract}
ABSTRAK
UJI FUNGSI SISTEM NITRIDASI ION UNTUK PERLAKUAN PERMUKAAN. Telah dilakukan uji fungsi sistem nitridasi ion untuk perlakuan permukaan. Uji fungsi bertujuan untuk mengetahui kinerja sistem nitridasi ion yang telah dirancang bangun untuk meningkatkan kekerasan permukaan logam. Dalam uji fungsi dilakukan uji kevakuman, penggunaan sistem nitridasi ion untuk nitridasi cuplikan (baja poros) dan karakterisasi cuplikan hasil nitridasi. Hasil uji kevakuman menunjukkan bahwa kevakuman dengan tabung reaktor plasma dan tanpa tabung reaktor plasma tidak menunjukkan perbedaan yang signifikan yaitu 3,7 × 10-2 mbar dan $3 \times 10^{-2}$ mbar sehingga kebocoran yang terjadi cukup kecil. Uji penggunaan sistem nitridasi ion menunjukkan bahwa: nitridasi dengan campuran gas $\mathrm{N}_{2}$ dan $\mathrm{H}_{2}$ dapat mengoptimalkan proses nitridasi sehingga diperoleh kekerasan yang lebih tinggi dibanding pada proses nitridasi dengan gas $N_{2}$ yaitu 868,5 KHN dengan kekerasan 4,05 kali kekerasan sebelum dinitridasi, sedangkan dengan gas $N_{2}$ didapatkan kekerasan 523,5 KHN. Pengamatan kedalaman difusi nitrogen dengan pengujian kekerasan penampang melintang dan struktur mikro mendekati sama terbukti bahwa pengukuran kekerasan melintang pada kedalaman 110 um hampir sama dengan material induk, sedangkan pada pengamatan struktur mikro perubahan butir terjadi sampai pada kedalaman $95 \mu \mathrm{m}$. Dengan hasil ini sistem nitridasi ion dapat berfungsi dengan baik untuk proses nitridasi sehingga dapat meningkatkan kekerasan permukaan.
\end{abstract}

\begin{abstract}
PERFORMANCE TESTING OF ION NITRIDATION SYSTEM FOR SURFACE TREATMENT. It has been carried out a performance testing of ion nitridation system for surface treatment. The purpose of the testing is to check the performance of constructed ion nitridation system for improving of surface hardness of the metal. Testing done cover the vacuum, utilization of ion nitridation system for treatment of the samples and its characterization. It's found that the vacuum system with reactor tube can achieve in order of $3.7 \times 10^{-2}$ mbar while without reactor tube, the vacuum in order of $3 \times 10^{-2} \mathrm{mbar}$. From this result it can be concluded that there is no leak of vacuum system. Utilization testing of the ion nitridation system done by introducing $\mathrm{N}_{2}$ and $\mathrm{N}_{2}+\mathrm{H}_{2}$ gas into reactor tube. It's found that, it the reactive gas only $\mathrm{N}_{2}$, the improving hardness that can be achieved only in order of $523.5 \mathrm{KHN}$. While if the reactive gas is the mixing of $\mathrm{N}_{2}+\mathrm{H}_{2}$, the improving hardness that can be achieved in order $868.5 \mathrm{KHN}$. It meant that there is an increasing in hardness in order of 4.05 times. Observation of the diffusion depth of the nitrogen has been done by measuring the hardness of the cross section microstructure samples. It's found that the diffusion depth of the nitrogen is in order of $110 \mu \mathrm{m}$. From micro structure observation, it's found that there are changing in grain size in order of 95 $\mu \mathrm{m}$ from the surface. From these result, it can be concluded that the constructed ion nitridation system can be operated well.
\end{abstract}

Key Word: materials science, surface treatment, ion nitridation.

\section{PENDAHULUAN}

Us ntuk mendukung perkembangan teknologi yang sangat pesat dibutuhkan bahan unggul yang mempunyai sifat-sifat sesuai dengan penggunaannya. Penggunaan bahan khususnya logam untuk komponen mesin harus mempunyai sifat mekanik yang baik sesuai dengan jenis kebutuhannya. Pada umumnya sifat-sifat logam yang dibutuhkan untuk komponen mesin adalah keras, liat dan tangguh, tahan korosi dan aus serta mempunyai koefisien gesek rendah. Untuk memenuhi kebutuhan logam yang mempunyai sifat-sifat ini sangat sedikit dibanding kebutuhan dan jika didapatkan harganya cukup mahal. Agar sifat-sifat yang dibutuhkan terpenuhi dan mudah didapatkan dengan harga yang relatif murah, maka dalam pembuatan komponen-komponen mesin menggunakan logam yang mempunyai sifat liat dan tangguh. Kemudian komponen mesin tersebut dilakukan perlakuan permukaan untuk mendapatkan sifat-sifat lain yang dibutuhkan. Beberapa jenis perlakuan permukaan secara konvensional untuk meningkatkan sifat mekanik permukaan logam antara lain cara karburasi, nitridasi, karbonitridasi, nyala api, dan induksi listrik ${ }^{[1,2,3]}$. 
Dengan kemajuan teknologi untuk memperbaiki sifat mekanik permukaan logam, saat ini mulai dikembangkan cara lain untuk membentuk lapisan tipis dan memperbaiki sifat-sifat pada permukaannya. Cara tersebut meliputi metode evaporasi, implantasi ion, plasma lucutan pijar RF, dan plasma lucutan pijar $\mathrm{DC}^{[4]}$. Pada penelitian ini digunakan metode plasma lucutan pijar DC yang diaplikasikan untuk proses nitridasi yang disebut nitridasi ion. Kelebihan dari metode ini yaitu dapat menghasilkan lapisan tipis baik dengan gas maupun bahan padat yang mempunyai titik leleh tinggi (plasma sputtering) ${ }^{[5]}$. Rancang bangun sistem nitridasi ion ini telah dilakukan di PTAPB-BATAN, untuk mengetahui kinerjanya maka dilakukan uji fungsi yaitu untuk proses nitridasi cuplikan dari bahan baja agar sifat keras permukaannya dapat meningkat.

\section{DASAR TEORI}

\section{Nitridasi}

Nitridasi adalah suatu proses pengerasan permukaan dengan menambahkan unsur nitrogen pada permukaan benda kerja (biasanya baja). Pada proses nitridasi secara konvensional dibedakan menjadi 2 (dua) cara yaitu proses nitridasi dengan gas (gas nitriding) dan proses nitridasi dengan cairan (liquid nitriding). Sehubungan dengan perkembangan teknologi telah dikembangkan teknologi terkini untuk proses nitridasi yaitu teknik nitridasi ion/plasma (ion/plasma nitriding) ${ }^{[6,7,8] .}$

\section{a. Proses nitridasi dengan gas (gas nitriding)}

Pada proses nitridasi ini menggunakan gas amonia $\left(\mathrm{NH}_{3}\right)$, nitridasi dilakukan di dalam tanur (furnace) pada suhu antara $460{ }^{\circ} \mathrm{C}-600{ }^{\circ} \mathrm{C}$. Pada suhu ini amonia akan berdesosiasi sehingga menghasilkan atom hidrogen dan nitrogen dengan reaksi sebagai berikut: ${ }^{[6]}$

$$
\mathrm{NH}_{3} \longrightarrow 3 / 2 \mathrm{H}_{2}+\mathrm{N}
$$

Dari desosiasi ini selanjutnya atom nitrogen larut pada permukaan benda yang dinitridasi sehingga membentuk nitrida. Proses nitridasi pada umumnya diterapkan untuk pengerasan peralatan (komponen mesin) yang terbuat dari baja karbon medium dan baja paduan yang mengandung unsur-unsur :Al, $\mathrm{Cr}$, Mo dan unsur lain yang memungkinkan bereaksi dengan unsur nitrogen. Unsur-unsur baja tersebut akan bereaksi dengan nitrogen yang larut secara interstisi sehingga membentuk nitrida-nitrida seperti: $\mathrm{Fe}_{2} \mathrm{~N}, \mathrm{Fe}_{3} \mathrm{~N}, \mathrm{Fe}_{4} \mathrm{~N}, \mathrm{Cr}_{2} \mathrm{~N}_{2} \mathrm{Mo}_{2} \mathrm{~N}$ maupun AIN. Penggunakan metode ini umumnya untuk valve guide, valve setting, gear, pinion, piston ring, dan spiral springs ${ }^{[6]}$.

\section{b. Proses nitridasi dengan cairan (liquid nitriding)}

Pada proses nitridasi ini menggunakan cairan garam seperti cyanide-cyianite salts yang mengandung $60 \%$ - 70\% NaCN (berat) dan 30\% - 40\% KCN (berat). Proses ini diawali pencairan garam pada daerah suhu 560 $570{ }^{\circ} \mathrm{C}$ dan waktu 1 - 2 jam untuk membasahi permukaan logam yang dinitridasi. Kemudian dilanjutkan dengan proses nitridasi pada suhu antara $565-595^{\circ} \mathrm{C}$ dengan waktu sampai 12 jam. Untuk menghasilkan nitrogen dengan reaksi sebagai berikut ${ }^{[6]}$ :

$$
4 \mathrm{NaCN}+2 \mathrm{O}_{2} \longrightarrow 4 \mathrm{NaCNO}
$$

Sodium cyanate ini bersifat tidak stabil sehingga terurai menghasilkan nitrogen sebagai berikut ${ }^{[6]}$ :

$$
4 \mathrm{NaCNO} \longrightarrow \mathrm{Na}_{2} \mathrm{CO}_{3}+2 \mathrm{NaCN}+\mathrm{CO}+2 \mathrm{~N}
$$

Selanjutnya atom nitrogen larut pada permukaan benda yang dinitridasi sehingga membentuk nitrida seperti pada nitridasi dengan gas $\mathrm{NH}_{3}$.

\section{c. Proses nitridasi dengan teknik nitridasi ion/ plasma}

Cara lain yang digunakan dalam proses nitridasi untuk pengerasan permukaan adalah dengan teknik nitridasi ion/plasma (ion/plasma nitriding) ${ }^{[6,7,8]}$. Teknik nitridasi ion/plasma termasuk teknologi terkini yang 
digunakan untuk proses pengerasan permukaan yang merupakan salah satu pengembangan pemanfaatan teknologi plasma. Pada nitridasi ion/plasma, proses nitridasi dilakukan dengan mendeposisikan ion nitrogen pada permukaan yang dikeraskan. Untuk membentuk ion nitrogen dilakukan dengan cara memplasmakan gas nitrogen di dalam tabung reaktor plasma sehingga terbentuk pasangan ion nitrogen dan elektron. Ion-ion nitrogen ini terdeposisi pada permukaan yang dikeraskan, sehingga terjadi difusi dan kelarutan secara interstisi membentuk lapisan nitrida. Jika yang dinitridasi adalah baja dengan unsur utama Fe maka akan terbentuk lapisan nitrida besi (FeN) pada permukaan. Nitrida besi (FeN) mempunyai sifat sangat keras sehingga membentuk lapisan keras pada permukaan baja yang dinitridasi.

\section{TATA KERJA}

Langkah-langkah dalam melakukan uji fungsi sistem nitridasi ion digambarkan dengan diagram alir yang ditunjukkan pada Gambar 1. Proses uji fungsi dimulai dengan persiapan yaitu konstruksi dan pengkondisian alat (sistem nitridasi ion) serta preparasi cuplikan yaitu pemotongan dan pemolesan bahan yang akan dinitridasi. Konstruksi merupakan perakitan bagian-bagian dari sistem nitridasi ion yang terdiri dari reaktor plasma, catu daya, sistem vakum, instrumen kendali dan sumber gas $\mathrm{N}_{2}$ serta kasis sehingga menjadi satu kesatuan yaitu sistem nitridasi ion. Pengkondisian alat dimulai dengan pengujian kevakuman dan pembangkitan plasma untuk nitridasi. Pengujian kevakuman adalah untuk mengetahui waktu yang diperlukan dalam persiapan nitridasi dan tingkat kevakuman akhir yang dapat dicapai. Tingkat kevakuman $(P)$ sebagai fungsi waktu ditentukan dengan persamaan $^{[9]}$

$$
P=\left(P_{i}-P_{u}\right) \exp \left\{\left[-\left(\frac{S_{p}}{V}\right) t\right] /\left[1+\left(\frac{S_{p}}{C}\right)\right]\right\}+P_{u}
$$

dengan Pi adalah kevakuman awal (mbar), Pu kevakuman akhir (mbar), Sp laju pemompaan teoritis (liter/detik), V volume ruang yang divakumkan (liter) dan $t$ waktu pemvakuman (detik). Peralatan untuk proses nitridasi dengan teknik nitridasi ion ditunjukkan pada Gambar 2. Peralatan tersebut dibuat di PTAPB yang merupakan aplikasi plasma untuk proses nitridasi. Pada uji fungsi ini juga dilakukan untuk nitridasi cuplikan dari baja poros. Proses nitridasi dilakukan dengan menggunakan gas $\mathrm{N}_{2}$ serta campuran $50 \% \mathrm{~N}_{2}$ dan $50 \% \mathrm{H}_{2}$.

\section{Pengujian hasil nitridasi}

Pengujian hasil nitridasi adalah untuk mengetahui fungsi sistem nitridasi ion untuk nitridasi material dalam bentuk cuplikan sehingga dapat merubah sifat mekanik permukaan. Pengujian ini meliputi pengamatan perubahan kekerasan dan pengamatan perubahan struktur mikro yang terjadi. Pengamatan perubahan kekerasan dilakukan dengan mengukur kekerasan cuplikan yang dinitridasi dengan berbagai variasi tekanan, jenis gas dan waktu. Pengukuran kekerasan juga dilakukan untuk bahan sebelum dinitridasi agar dapat diketahui perubahan kekerasannya. Dalam pengamatan struktur mikro untuk mengamati perubahan struktur mikro akibat terbentuknya nitrida hasil reaksi nitrogen dengan logam induk (cuplikan). Alat yang digunakan untuk pengukuran kekerasan adalah Digital Micro Hardness Tester jenis MXT 70 dan untuk pengamatan struktur mikro adalah mikroskop optik Zeis jenis Axiolab LR $66238 \mathrm{C}$. 


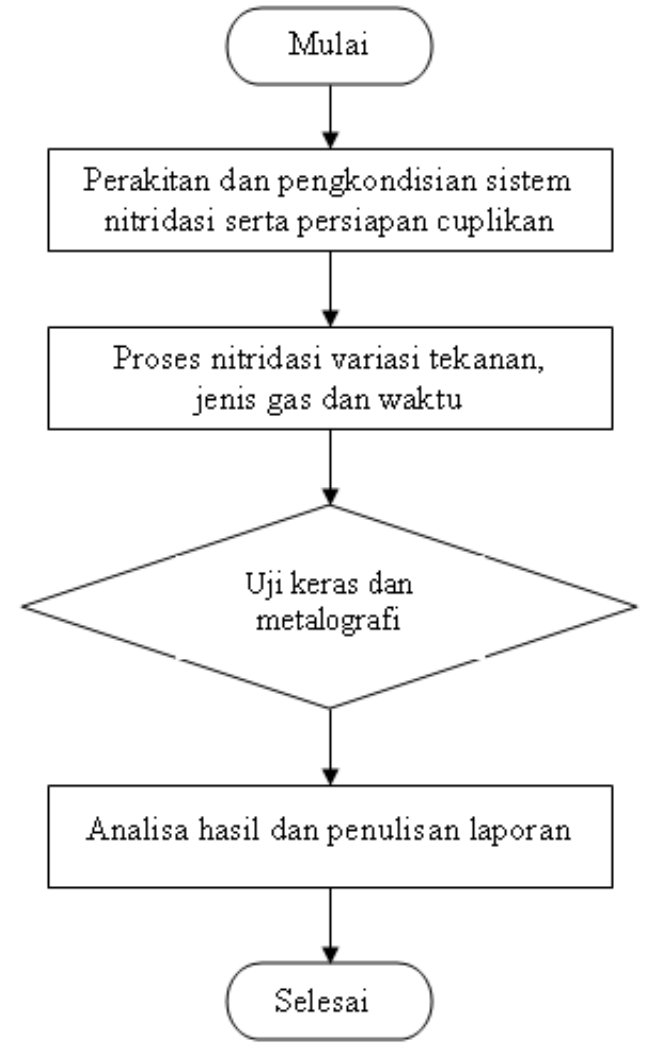

Gambar 1. Diagram alir uji fungsi sistem nitridasi ion.

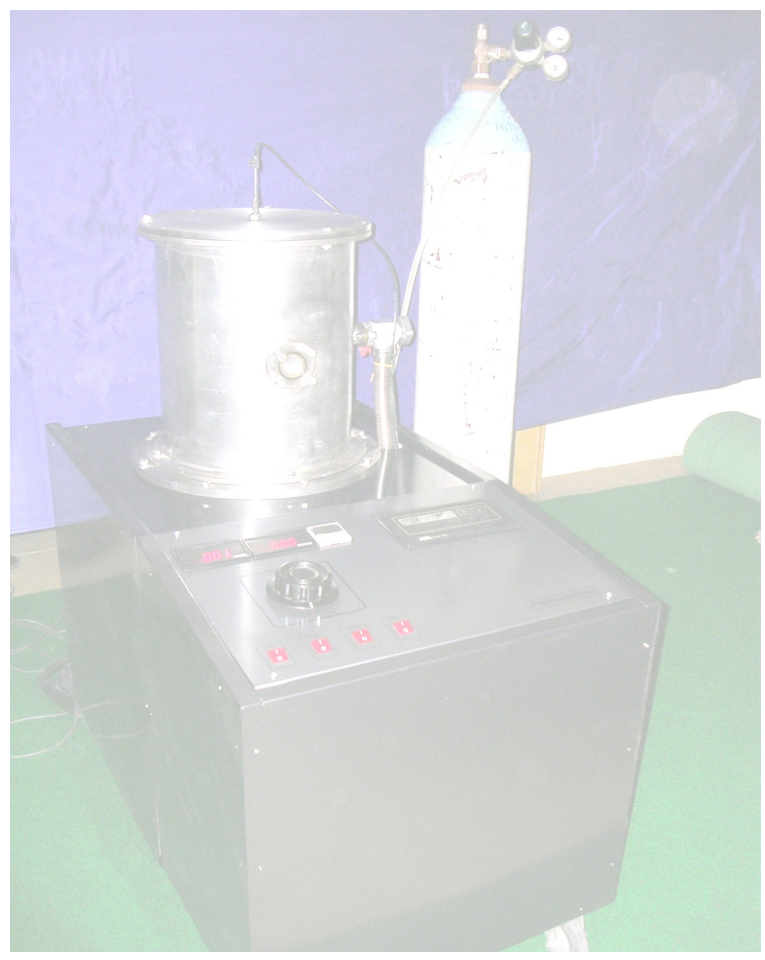

Gambar 2. Sistem nitridasi ion/plasma. 


\section{HASIL DAN PEMBAHASAN}

\section{Pengujian Kevakuman}

Pengujian kevakuman adalah untuk mengetahui tingkat kevakuman akhir tabung reaktor plasma di mana benda kerja yang dinitridasi ditempatkan. Hal ini dilakukan karena sangat berkaitan dengan laju kebocoran dari tabung reaktor sehingga mempengaruhi jumlah atom pengotor pada proses nitridasi. Jika laju kebocoran gas (udara) ke dalam tabung makin besar maka menyebabkan jumlah atom pengotor pada proses nitridasi makin besar dan menyebabkan hasil nitridasi tidak optimum. Pengujian kevakuman ini dilakukan dengan pompa rotari Edwards jenis E2M2 yang digunakan pada sistem nitridasi ion dan hasilnya ditunjukkan pada Gambar 3. Dari hasil perhitungan dengan persamaan (1) dan pengujian didapatkan perbedaan yang cukup signifikan. Dalam perhitungan, setelah divakumkan selama 15 menit didapatkan kevakuman 0,10031 mbar (1,0031.10-1 mbar) sedangkan pada pengujian didapatkan 0,16 mbar (1,6 . 10-1 mbar). Hal ini disebabkan dalam perhitungan didasarkan dalam kondisi bersih untuk standar komponen sistem vakum yaitu dengan mengabaikan terjadinya pelepasan gas (outgassing) serta kondisi pompa vakum sesuai dengan spesifikasi. Tetapi pada instalasi sulit didapatkan kondisi standar tersebut karena kesulitan dalam proses perlakuan komponen sistem vakum antara lain pemanasan dalam ruang vakum (bake) untuk membersihkan permukaan komponen. Dengan demikian akibat dari kotoran-kotoran yang menempel pada permukaan komponen setelah divakumkan terjadi pelepasan gas (outgassing). Dengan adanya pelepasan gas maka beban pompa bertambah dan sulit untuk mencapai kevakuman sesuai dengan perhitungan. Hal ini terbukti dari hasil pengujian (Gambar 3) yang menunjukkan selisih kevakuman dari hasil perhitungan dan pengujian. Berdasarkan perhitungan kevakuman yang dapat dicapai adalah 1. $10^{-2}$ mbar dengan waktu pemompaan 15 menit, sedangkan hasil pengujian didapatkan kevakuman 1,6 .10-1 mbar. Jika tabung reaktor tersebut divakumkan terus dengan waktu pemompaan 40 menit dicapai kevakuman

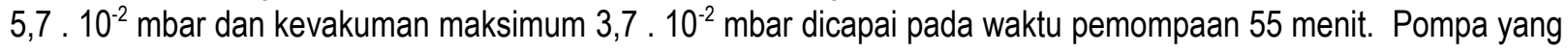
digunakan tersebut sudah mempunyai umur pakai sekitar 20 tahun dan berdasarkan pengujian (tanpa tabung reaktor) kevakuman yang dicapai $3 \cdot 10^{-2}$ mbar, sedangkan berdasarkan spesifikasi mempunyai kemampuan 5 . $10^{-3}$ mbar. Berdasarkan pengujian tersebut menunjukkan bahwa pompa sudah mengalami penurunan kemampuan yang disebabkan umur pemakaian. Untuk pengujian dengan tabung reaktor dan tanpa tabung reaktor tidak menunjukkan perbedaan kevakuman yang signifikan sehingga kebocoran yang terjadi cukup kecil walaupun jika dibandingkan dengan perhitungan berdasarkan spesifikasi pompa yang digunakan cukup signifikan.

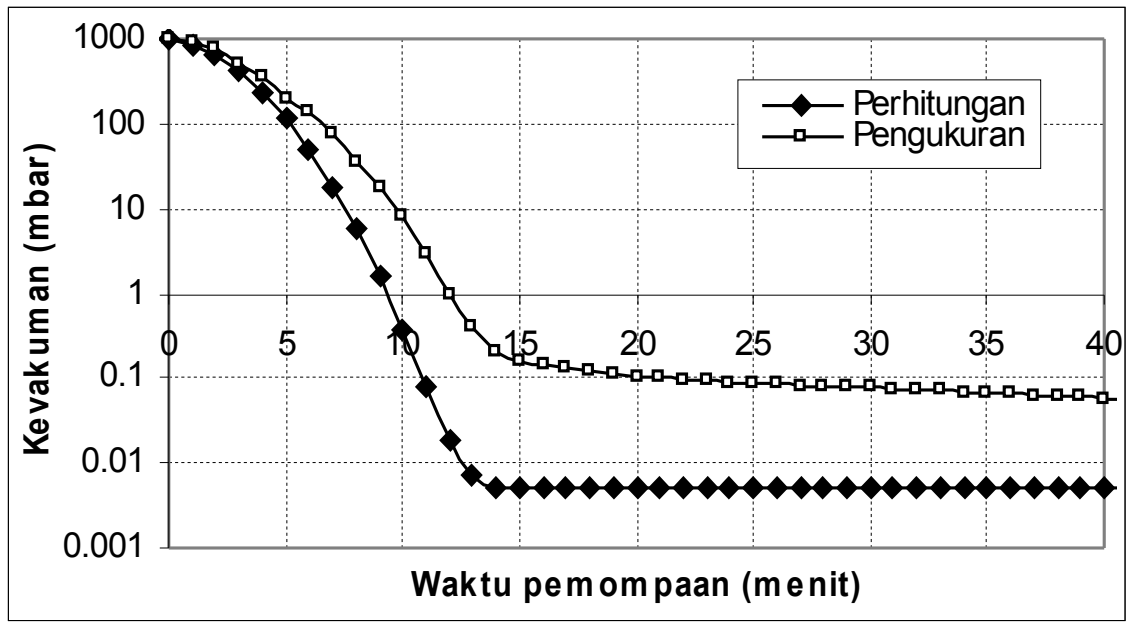

Gambar 3. Kevakuman sebagai fungsi waktu untuk pemompaan dengan pompa rotari Edwards jenis E2M2.

\section{Uji Kekerasan dan Struktur Mikro}

Perubahaan nilai kekerasan akibat nitridasi pada suatu logam disebabkan adanya perubahan struktur mikro dan komposisi logam tersebut. Dalam proses nitridasi, unsur nitrogen yang ditambahkan dapat mengubah struktur mikro dan komposisi dari logam induk sehingga mengubah sifat-sifat mekanisnya. Untuk proses nitridasi dengan 
teknik nitridasi ion, atom nitrogen diionisasi dalam bentuk plasma sehingga terbentuk pasangan ion nitrogen dan elektron. Ion nitrogen ini dideposisikan pada permukaan logam yang dinitridasi sehingga membentuk lapisan tipis nitrogen, selanjutnya ion nitrogen berdifusi dan larut secara interstisi membentuk lapisan nitrida logam pada permukaan cuplikan yang dinitridasi (material induk). Nitrida logam ini mempunyai kekerasan yang tinggi dan struktur mikro yang berbeda dibanding logam induknya. Untuk mengetahui perubahan kekerasan dan struktur mikro permukaan hasil nitridasi dilakukan pengujian kekerasan dan struktur mikro. Pengujian kekerasan dilakukan untuk cuplikan sebelum dinitridasi dan sesudah dinitridasi yang hasilnya ditunjukkan pada Gambar 4, Gambar 5 dan Gambar 6. Pada Gambar 4a ditunjukkan hasil pengujian kekerasan sebagai fungsi tekanan di dalam tabung reaktor plasma pada berbagai kondisi waktu nitridasi dengan gas $\mathrm{N}_{2}$, sedangkan pada Gambar $4 b$ ditunjukkan hasil pengujian kekerasan pada kondisi yang hampir sama untuk nitridasi dengan gas campuran $\mathrm{N}_{2}$ dan $\mathrm{H}_{2}$. Pada proses nitridasi dilakukan pada suhu $500{ }^{\circ} \mathrm{C}$ untuk beberapa variasi tekanan di dalam tabung reaktor plasma agar didapatkan kondisi tekanan yang optimum. Variasi tekanan dimulai dari tekanan 0,6 mbar sampai 1,6 mbar untuk nitridasi dengan gas $\mathrm{N}_{2}$ dan 1.2 mbar sampai 1,8 mbar untuk nitridasi dengan campuran gas $\mathrm{N}_{2}$ dan $\mathrm{H}_{2}$ dengan komposisi $50 \% \mathrm{~N}_{2}$ dan $50 \% \mathrm{H}_{2}$ (volume), masing-masing variasi dilakukan dengan kelipatan 0,2 mbar. Hasil pengujian kekerasan untuk cuplikan sebelum dinitridasi adalah 214,7 KHN. Sedangkan hasil pengujian cuplikan setelah dinitridasi menunjukkan bahwa makin tinggi tekanan reaktor plasma pada proses nitridasi, makin tinggi kekerasan yang dihasilkan dan didapatkan kekerasan maksimum $523,5 \mathrm{KHN}$ pada tekanan 1,4 mbar dan waktu nitridasi 3 jam dengan gas $\mathrm{N}_{2}$ (Gambar 4a). Hal ini disebabkan makin tinggi tekanan reaktor plasma makin tinggi rapat atom gas nitrogen sehingga makin banyak yang terdeposisi dan menempel pada permukaan cuplikan selanjutnya berdifusi secara interstisi membentuk lapisan nitrida besi (FeN). Setelah tekanan mencapai di atas 1,4 mbar dimungkinkan terjadi kelebihan atom nitrogen yang terdeposisi dari pada yang berdifusi sehingga menimbulkan penumpukan atom nitrogen pada permukaan dan menyebabkan penurunan kekerasan. Untuk hasil nitridasi dengan gas campuran $\mathrm{N}_{2}$ dan $\mathrm{H}_{2}$ didapatkan kekerasan maksimum 868,5 KHN pada tekanan 1,4 mbar dan waktu nitridasi 4 jam (Gambar 4b). Jika tekanan gas di reaktor plasma dinaikkan memberikan dampak yang sama seperti pada nitridasi dengan gas $\mathrm{N}_{2}$. Untuk proses nitridasi dengan gas secara konvensional, gas yang digunakan adalah gas amonia $\left(\mathrm{NH}_{3}\right)$. Pada suhu nitridasi gas tersebut terdesosiasi membentuk nitrogen dan hidrogen. Gas hidrogen pada proses ini untuk menurunkan tekanan partial gas nitrogen yang mengakibatkan potensial nitridasi lebih rendah sehingga memperkecil lapisan puth sampai pada konsentrasi nitrogen yang terlarut, lapisan putih ini menyebabkan kegetasan lapisan permukaan sehingga dapat menyebabkan pengelupasan $(\text { spalling })^{[6]}$. Dengan makin tipis lapisan putih makin baik proses nitridasi atau makin optimal nitridasi yang dihasilkan. Berdasarkan argumentasi tersebut, pada proses nitridasi ion dengan campuran gas $\mathrm{N}_{2}$ dan $\mathrm{H}_{2}$ dapat mengoptimalkan proses nitridasi sehingga diperoleh kekerasan yang lebih tinggi dibanding pada proses nitridasi dengan gas $\mathrm{N}_{2}$.

Berdasarkan hasil pengujian kekerasan tersebut didapatkan kekerasan 2,44 kali dari kekerasan sebelum dinitridasi untuk nitridasi dengan gas $\mathrm{N}_{2}$ dan 4,05 kali dari kekerasan sebelum dinitridasi untuk nitridasi dengan gas $\mathrm{N}_{2}$ dan $\mathrm{H}_{2}$. Hasil ini cukup bagus karena pada umumnya kekerasan hasil nitridasi antara 2 sampai 3 kali (2,7 kali) kekerasan sebelum dinitridasi ${ }^{10}$.

Pada Gambar 5 ditunjukkan hasil pengujian kekerasan sebagai fungsi waktu nitridasi pada berbagai kondisi tekanan di dalam reaktor plasma. Kekerasan hasil nitridasi dengan gas $\mathrm{N}_{2}$ ditunjukkan pada Gambar $5 \mathrm{a}$, sedangkan untuk nitridasi dengan gas campuran $\mathrm{N}_{2}$ dan $\mathrm{H}_{2}$ ditunjukkan pada Gambar $5 b$. Untuk nitridasi dengan gas $\mathrm{N}_{2}$ pada berbagai kondisi tekanan menunjukkan bahwa makin lama waktu nitridasi (untuk waktu 1 jam - 3 jam) kekerasan makin meningkat. Hal ini disebabkan karena untuk waktu nitridasi 1 jam atom-atom nitrogen yang terdeposisi pada permukaan masih sedikit, jika waktu nitridasi ditambah menjadi 3 jam maka jumlah atom nitrogen yang terdeposisi dan berdifusi makin banyak. Atom-atom nitrogen yang berdifusi ke permukaan akan bereaksi dengan atom-atom $\mathrm{Fe}$ untuk membentuk fase baru yaitu $\mathrm{FeN}$ yang memiliki sifat yang keras, sehingga penambahan nitrogen mengakibatkan penambahan kekerasan pada permukaan yang dinitridasi. Pada waktu nitridasi 4 jam bahkan mengalami penurunan kekerasan hal ini dimungkinkan karena dengan tambahan atom nitrogen maka fase keras akan bergeser menjadi fase lunak atau atom-atom nitrogen tersebut hanya menumpuk 
pada permukaan yang tidak sempat berdifusi dengan material induk (Fe). Jadi makin lama proses nitridasi tidak diperoleh kekerasan yang maksimal melainkan kekerasan akan menurun.

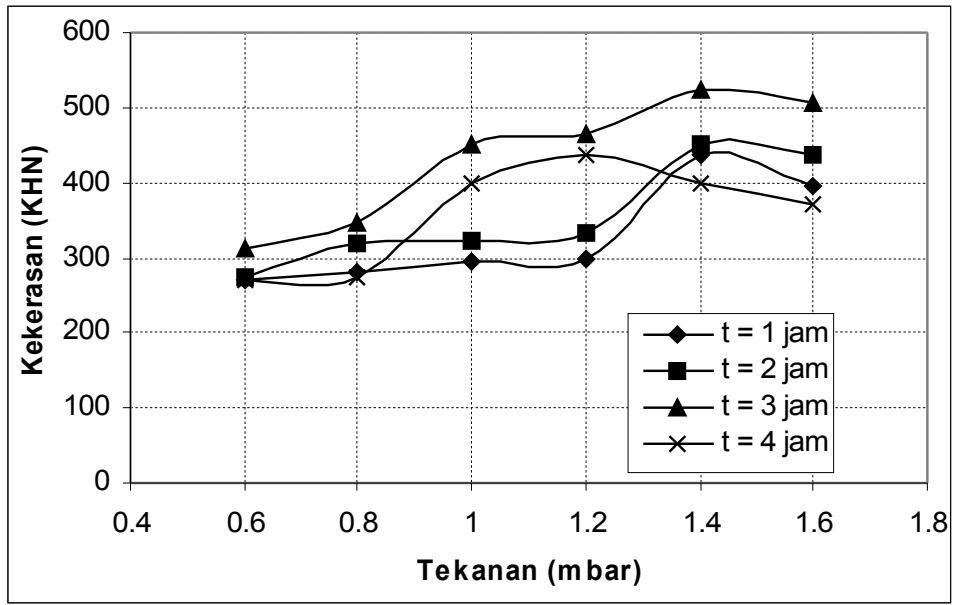

a. Nitridasi dengan gas $\mathrm{N}_{2}$

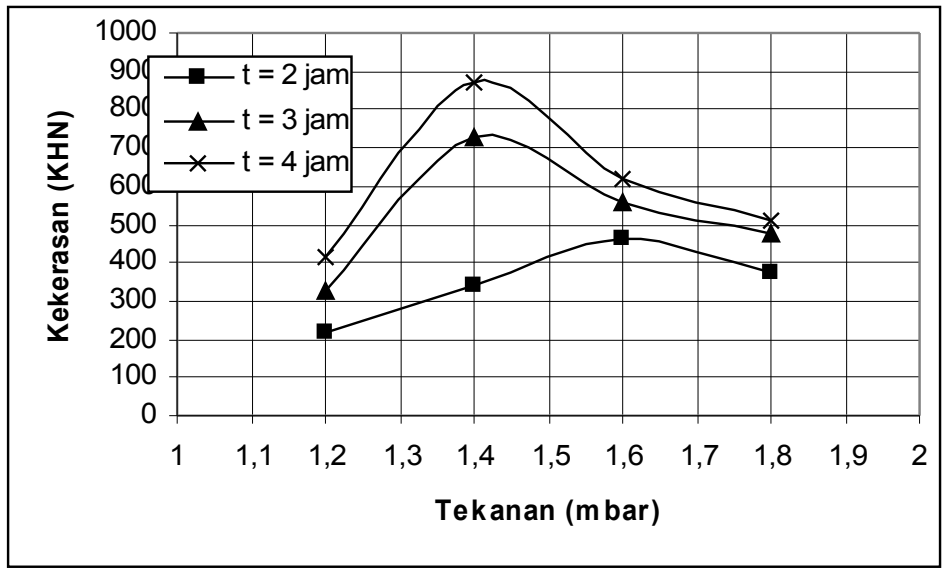

b. Nitridasi dengan campuran gas $\mathrm{N}_{2}$ dan $\mathrm{H}_{2}$

Gambar 4. Angka kekerasan sebagai fungsi tekanan untuk berbagai variasi waktu.

Untuk nitridasi dengan gas campuran $\mathrm{N}_{2}$ dan $\mathrm{H}_{2}$ pada berbagai kondisi tekanan menunjukkan bahwa makin lama waktu nitridasi kekerasan makin meningkat. Nitridasi dilakukan mulai dengan waktu 1 jam sampai dengan 4 jam, walaupun telah dilakukan sampai 4 jam (lebih lama dibanding dengan waktu nitridasi menggunakan gas $\mathrm{N}_{2}$ ) belum didapatkan kekerasan maksimum. Hal ini disebabkan dengan campuran $\mathrm{N}_{2}$ dan $\mathrm{H}_{2}$ memberikan potensial nitridasi lebih rendah $^{[6]}$, sehingga memerlukan waktu nitridasi lebih lama dan dimungkinkan memberikan kesetimbangan antara atom $\mathrm{N}_{2}$ yang terdeposisi dengan yang berdifusi serta bereaksi membentuk FeN. Dengan kesetimbangan ini maka dihasilkan kekerasan yang lebih tinggi.

Pada Gambar 6 ditunjukkan hasil pengujian kekerasan sebagai fungsi kedalaman penetrasi hasil nitridasi. Pengujian ini dilakukan untuk nitridasi dengan gas $\mathrm{N}_{2} 50 \%$ (volume) dan $\mathrm{H}_{2} 50 \%$ (volume) dengan 3 variasi tekanan di dalam tabung reaktor plasma dan waktu nitridasi 4 jam. Pengujian dilakukan dengan mengukur kekerasan tiap perubahan ke dalam $10 \mu \mathrm{m}$ hingga ke dalam $110 \mu \mathrm{m}$. Dari hasil pengujian profil kekerasan ini menunjukkan bahwa kekerasan cuplikan yang telah dinitridasi menurun sebagai fungsi kedalaman. Pada permukaan didapatkan kekerasan $868,5 \mathrm{KHN}$, sedangkan pada kedalaman $30 \mu \mathrm{m}$ didapatkan kekerasan $439 \mathrm{KHN}$ serta pada kedalaman $60 \mu \mathrm{m}$ didapatkan kekerasan $279 \mathrm{KHN}$. Selanjutnya makin kedalam dari permukaan, kekerasan makin mendekati kekerasan material induk dan pada kedalaman $100 \mu \mathrm{m}$ didapatkan kekerasan 233 $\mathrm{KHN}$ serta pada kedalaman $110 \mu \mathrm{m}$ didapatkan kekerasan $226 \mathrm{KHN}$. Hal ini menunjukkan bahwa penetrasi akibat 
difusi nitrogen hanya terjadi pada permukaan material dengan kedalaman yang terbatas yaitu sekitar $100 \mu \mathrm{m}$ sehingga hanya meningkatkan kekerasan pada permukaan dan tidak mempengaruhi sifat-sifat mekanik pada material induk.

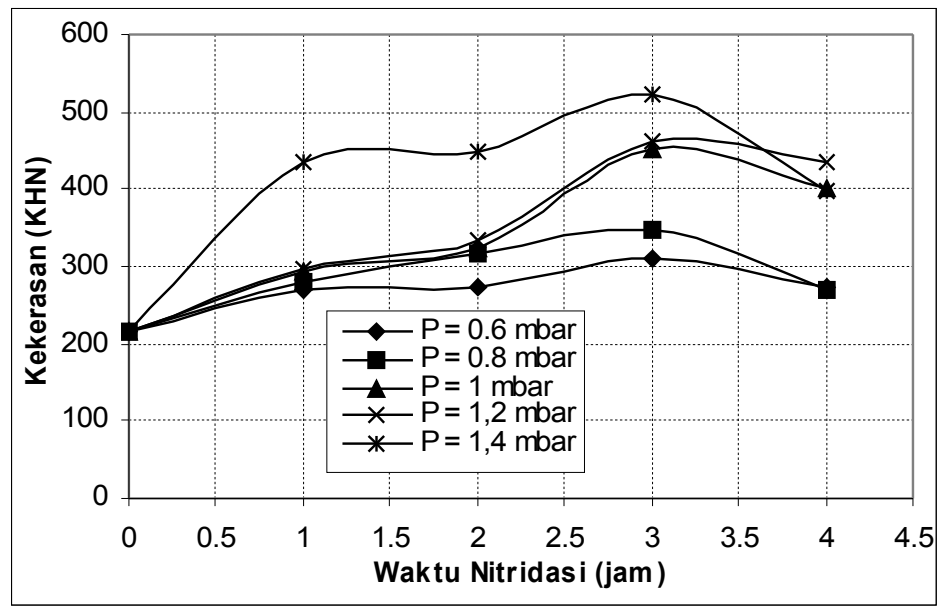

a. Nitridasi dengan gas $\mathrm{N}_{2}$

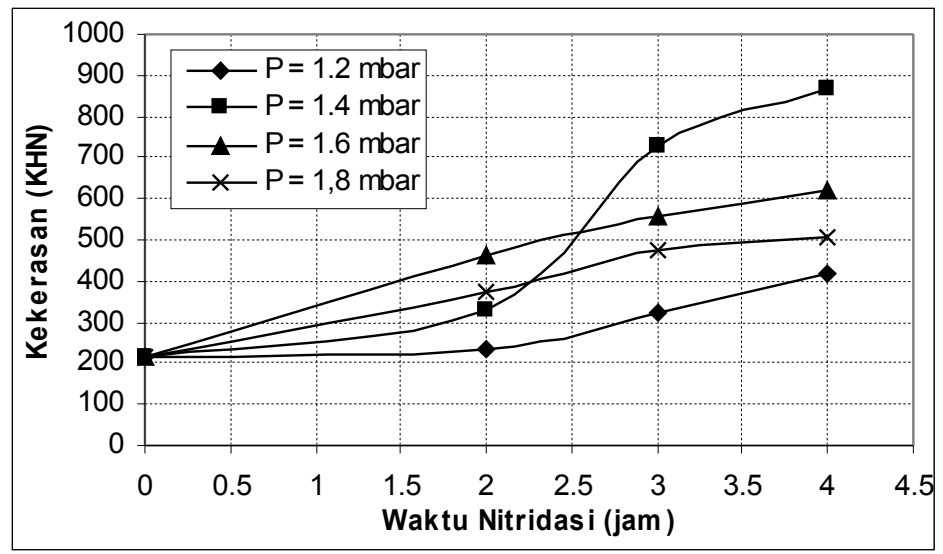

b. Nitridasi dengan gas $\mathrm{N}_{2}$ dan $\mathrm{H}_{2}$

Gambar 5. Angka kekerasan sebagai fungsi variasi waktu nitridasi untuk berbagai tekanan.

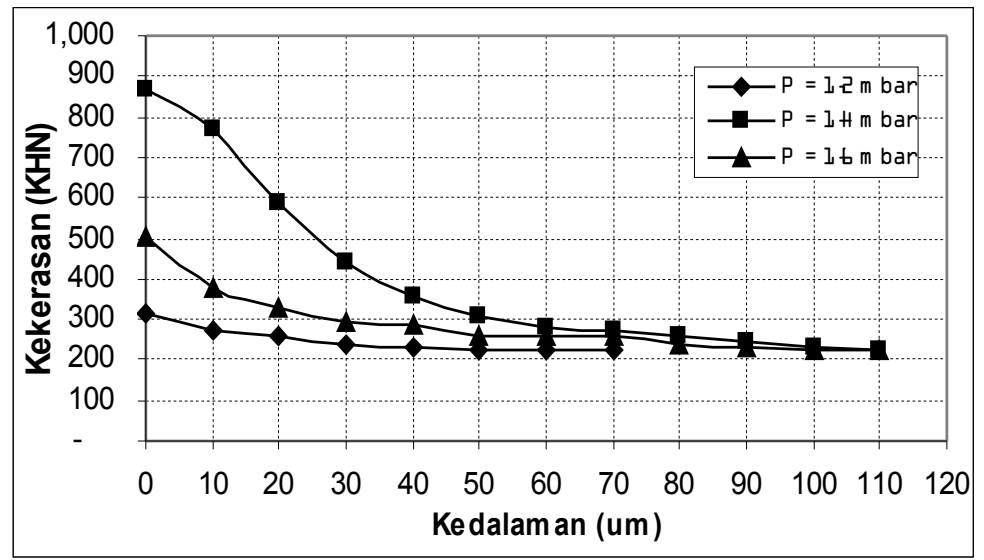

Gambar 6. Angka kekerasan sebagai fungsi kedalaman penetrasi untuk 3 variasi tekanan dengan campuran gas $\mathrm{N}_{2}$ dan $\mathrm{H}_{2}$. 


\section{Uji Metalografi}

Dalam pengujian metalografi dilakukan untuk mengamati perubahan struktur mikro dari bahan setelah dinitridasi. Pengamatan ini dilakukan dengan mengamati struktur pada penampang melintangnya sehingga dapat mengamati di dekat permukaan dan kedalaman difusi nitrogen yang terjadi. Hasil pengamatan struktur mikro pada penampang melintang dari cuplikan sesudah dinitridasi pada suhu $500{ }^{\circ} \mathrm{C}$ dengan waktu 4 jam ditunjukkan pada Gambar 7. Pada Gambar 7 terlihat bahwa terjadi perubahan lapisan permukaan akibat nitridasi. Perubahan ini ditunjukkan dengan adanya pertumbuhan butir yang halus pada permukaan. Hasil pengukuran berdasarkan pengamatan struktur mikro (perubahan butir) didapatkan kedalaman difusi sekitar $95 \mu \mathrm{m}$, sedangkan berdasarkan pengujian kekerasan penampang melintang sekitar $100 \mu \mathrm{m}$. Dengan hasil ini menunjukkan bahwa kedalaman penetrasi pada suhu nitridasi $500^{\circ} \mathrm{C}$ dengan waktu 4 jam sekitar $95 \mu \mathrm{m}-100 \mu \mathrm{m}$.

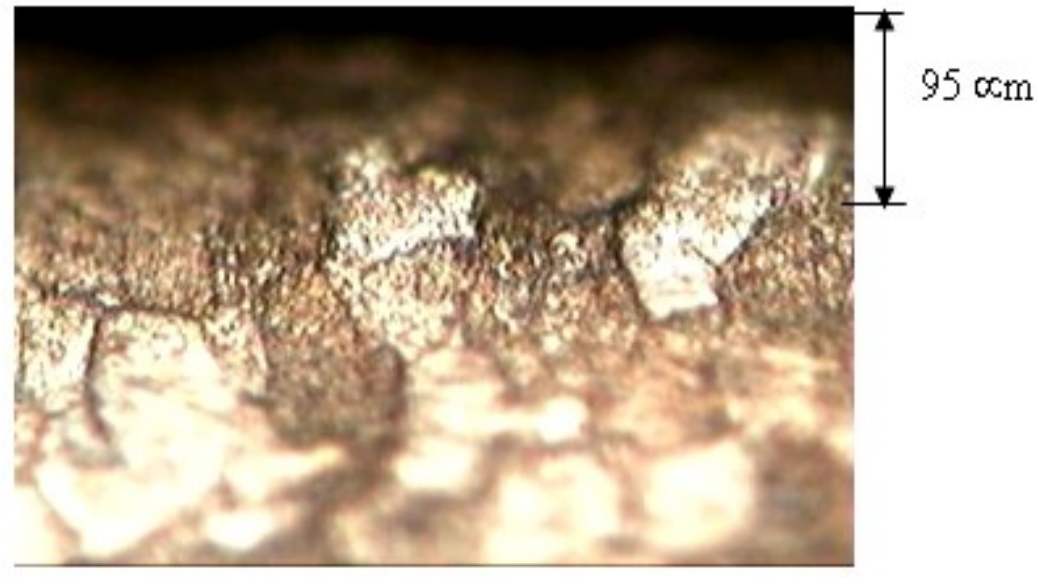

Gambar 7. Struktur mikro pada penampang melintang cuplikan sesudah proses nitridasi pada suhu $500{ }^{\circ} \mathrm{C}$ dengan waktu 4 jam.

\section{KESIMPULAN}

Dari hasil uji fungsi sistem nitridasi ion untuk perlakuan permukaan dapat disimpulkan sebagai berikut :

1. Pengujian kevakuman dengan tabung reaktor plasma dan tanpa tabung reaktor plasma tidak menunjukkan perbedaan kevakuman yang signifikan yaitu $3,7 \times 10^{-2}$ mbar dan $3 \times 10^{-2}$ mbar sehingga kebocoran yang terjadi cukup kecil.

2. Proses nitridasi ion dengan campuran gas $\mathrm{N}_{2}$ dan $\mathrm{H}_{2}$ dapat mengoptimalkan proses nitridasi sehingga diperoleh kekerasan yang lebih tinggi dibanding pada proses nitridasi dengan gas $\mathrm{N}_{2}$ yaitu $868,5 \mathrm{KHN}$ dengan kekerasan 4,05 kali kekerasan sebelum dinitridasi, sedangkan dengan gas $\mathrm{N}_{2}$ didapatkan kekerasan 523,5 KHN.

3. Pengamatan kedalaman difusi nitrogen dengan pengujian kekerasan penampang melintang dan struktur mikro mendekati sama dan terbukti bahwa pengukuran kekerasan penam-pang melintang pada kedalaman $110 \mu \mathrm{m}$ hampir sama dengan material induk, sedangkan pada pengamatan struktur mikro perubahan butir terjadi sampai pada kedalaman $95 \mu \mathrm{m}$.

Dengan hasil ini sistem nitridasi ion berfungsi dengan baik untuk proses nitridasi sehingga dapat meningkatkan kekerasan permukaan.

\section{DAFTAR PUSTAKA}

1. DIETER, G.E., Metalurgi Mekanik, Penerjemah Sriati Djaprie, Penerbit Erlangga, Jakarta, 1987.

2. ALEXANDER W.O, Dasar-dasar Metalurgi Untuk Rekayasawan, Penerbit Gramedia, Jakarta, 1991. 
3. -------, Metal Hand Book, Heat Treating, Cleaning and Finishing Volume 2, $8^{\text {th }}$ Edition, ASTM, United State of America, 1988.

4. KONUMA, M., Film Deposition By Plasma Techniques, Spinger Verlag, Berlin, 1992.

5. WASA, K. AND HAYAKAWA, S., Hand Book of Sputter Deposition Technology, Nayes Publication, New York, 1992.

6. SINHA,A.K., Physical Metallurgy Handbook, Mc Graw-Hill, New York, 2003.

7. -------, Techcommentary lon Nitriding; Improve Metallurgical Properties and Increase Productivity Using Ion Nitriding, EPRI Center for Materials Fabrication, Vol. 2-No 5., Colombus, 1994..

8. MUKHERJEE, S., Plasma Based Nitrogen Incorporation Techniques for Surface Modification, Current Science, Vol.83-No.3, Gandhinagar, India, 2002.

9. ROTH, A., Vacuum Technology, North-Holland Publishing Company, New York, 1979.

10. UEDA, M., GOMES, G.F., KOSTOV, K.G., REUTHER, H., LEPIENSKI, C.M., SOARES, P.C., TOKAI, O., AND SILVA, M.M., Results from Experiments on Hybrid Plasma Immersion Ion Implantation/Nitriding Processing of Materials, Brazillian Journal of Physics, Vol. 34 no 4b, Sao Paulo, 2004. 